\title{
Neuropsychological functioning in early and chronic stages of schizophrenia and psychotic bipolar disorder
}

\author{
Margo W. Menkes ${ }^{a}$, Kristan Armstrong ${ }^{a}$, Jennifer Urbano Blackford ${ }^{a, b}$, Stephan Heckers ${ }^{a}$, \\ and Neil D. Woodward ${ }^{a}$ \\ aDepartment of Psychiatry and Behavioral Sciences, Vanderbilt University Medical Center, \\ Nashville, TN \\ ${ }^{\mathrm{b}}$ Research Service, Tennessee Valley HealthCare System, US Department of Veterans Affairs
}

\section{Abstract}

Background: Neuropsychological impairment is common in schizophrenia and psychotic bipolar disorder. It has been hypothesized that the pathways leading to impairment differ between disorders. Cognitive impairment in schizophrenia is believed to result largely from atypical neurodevelopment, whereas bipolar disorder is increasingly conceptualized as a neuroprogressive disorder. The current investigation tested several key predictions of this hypothesis.

Methods: Current neuropsychological functioning and estimated premorbid intellectual ability were assessed in healthy individuals $(n=260)$ and a large, cross-sectional sample of individuals in the early and chronic stages of psychosis $(n=410)$. We tested the following hypotheses: 1$)$ cognitive impairment is more severe in schizophrenia in the early stage of psychosis; and 2) cognitive decline between early and chronic stages is relatively greater in psychotic bipolar disorder. Additionally, individuals with psychosis were classified as neuropsychologically normal, deteriorated, and compromised (i.e. below average intellectual functioning) to determine if the frequencies of neuropsychologically compromised and deteriorated patients were higher in schizophrenia and psychotic bipolar disorder, respectively.

Results: Neuropsychological impairment in the early stage of psychosis was more severe in schizophrenia. Psychotic bipolar disorder was not associated with relatively greater cognitive decline between illness stages. The frequency of neuropsychologically compromised patients was higher in schizophrenia; however, substantial portions of both schizophrenia and psychotic bipolar disorder patients were classified as neuropsychologically compromised and deteriorated.

Corresponding Author: Neil D. Woodward, PhD, Vanderbilt Psychiatric Hospital, Suite 3057, $160123^{\text {rd }}$ Ave. S., Nashville, TN 37212, Phone: 615.322.8361, Fax: 615.936.3563, neil.d.woodward@ vumc.org.

Contributors

MWM and NDW conceptualized the study and conducted data analyses. KA helped with data analysis and edited the manuscript. JUB provided feedback on the analysis plan and edited the manuscript. SH edited the manuscript. MWM wrote the original draft of and prepared the manuscript. NDW finalized data analyses and contributed significantly to editing the manuscript.

Publisher's Disclaimer: This is a PDF file of an unedited manuscript that has been accepted for publication. As a service to our customers we are providing this early version of the manuscript. The manuscript will undergo copyediting, typesetting, and review of the resulting proof before it is published in its final citable form. Please note that during the production process errors may be discovered which could affect the content, and all legal disclaimers that apply to the journal pertain.

Conflict of Interest

No commercial support was received for the preparation of this manuscript and the authors have no conflicts of interest to report. 
Conclusions: While schizophrenia is associated with relatively greater neurodevelopmental involvement, psychotic bipolar disorder and schizophrenia cannot be strictly dichotomized into purely neuroprogressive and neurodevelopmental illness trajectories; there is evidence of both processes in each disorder.

\section{Keywords}

Early stage psychosis; cognition; schizophrenia; bipolar disorder

\section{INTRODUCTION}

Whether schizophrenia and psychotic bipolar disorder represent separate disease entities with unique pathophysiologies and illness trajectories remains an area of intense investigation. Examining neuropsychological functioning across psychotic disorders may help address this question. Studies comparing cognitive function between schizophrenia and bipolar disorder have yielded mixed findings. Several relatively large investigations and meta-analyses of cognitive function in chronic patients found few, if any, differences between schizophrenia and psychotic bipolar disorder (Bora et al., 2009; Reichenberg et al., 2009; Simonsen et al., 2011); although there are exceptions (Seidman et al., 2002). In contrast, most studies in early stage patients found greater cognitive impairment in schizophrenia than psychotic bipolar disorder (Barrett et al., 2009; Dickerson et al., 2011; Hill et al., 2009; Mojtabai et al., 2000; Zanelli et al., 2010). Indeed, compared to healthy subjects, cognitive impairment in early stage bipolar disorder is mild and perhaps limited to specific cognitive domains (Barrett et al., 2009; Zanelli et al., 2010).

Combined with the broader literature on neuropsychological functioning in psychosis, the findings reviewed above led to the hypothesis that the trajectories of cognitive impairment differ between schizophrenia and bipolar disorder (Lewandowski et al., 2011; Parellada et al., 2017). Specifically, schizophrenia is conceptualized as a neurodevelopmental disorder characterized by early, premorbid deficits in cognitive function, additional decline during the prodromal/peri-onset period (or failure to demonstrate normal cognitive maturation), and a relatively static course following illness onset (Gold et al., 1999; Hoff et al., 2005;

Reichenberg et al., 2010). In contrast, bipolar disorder is increasingly conceptualized as a neuroprogressive illness characterized by normal cognitive development, mild focal deficits in the early stage of the illness, and progressive decline over time following illness onset, with the chronic stage of bipolar disorder being indistinguishable from schizophrenia (Reichenberg et al., 2009; Simonsen et al., 2011; Zubieta et al., 2001).

So far, the hypothesis of distinct neuropsychological trajectories is based on few investigations that, in some cases, included relatively few individuals in the early stage of psychosis. Moreover, growing awareness of the heterogeneity in cognitive impairment within psychotic disorders further suggests that cognitive trajectories in schizophrenia and psychotic bipolar disorder may not be strictly neurodevelopmental and neuroprogressive, respectively. Studies in schizophrenia have identified three cognitive subgroups that differ from one another based on not only current cognitive abilities, but also the discrepancy between current cognitive functioning and estimated premorbid intellectual functioning (i.e. 
IQ). They include: 1) a neuropsychologically "normal" group characterized by average or higher premorbid IQ and current cognitive functioning; 2) a neuropsychologically "deteriorated" group defined by average premorbid IQ, but impaired current cognitive abilities; and 3) a neuropsychologically "compromised" group that demonstrates low premorbid IQ (Badcock, Dragović, Waters, \& Jablensky, 2005; Weickert et al., 2000; Woodward \& Heckers, 2015). While these subgroups are typically defined based on crosssectional cognitive data, the assumption is that cognitive impairment in compromised and deteriorated patients results from atypical early brain development and neurodegeneration/ later cerebral dysmaturation, respectively (Weickert et al., 2000; Woodward, 2016). Neuroimaging findings showing that abnormalities in brain structure are more prominent in deteriorated and compromised patients, with the latter exhibiting smaller intracranial volumes suggestive of cerebral hypoplasia, support this assumption (Czepielewski et al., 2016; Weinberg et al., 2016; Woodward and Heckers, 2015).

The current investigation leveraged a large, cross-sectional cohort of psychosis patients $(n>400)$ to better understand cognitive impairment across psychotic disorders and illness stages, and test several predictions of the different trajectories hypothesis described above. First, we tested the hypothesis that cognitive impairment is more severe in schizophrenia than psychotic bipolar disorder in a large sample of early stage psychosis patients $(n>150)$. Next, using our large sample of healthy subjects $(n>250)$ as normative data to control for the effects of demographic variables, we tested the hypothesis that there is a diagnosis by illness stage interaction characterized by relatively greater cognitive decline in psychotic bipolar disorder than schizophrenia, a key prediction of the different illness trajectories model. Finally, we examined the frequency of the three cognitive subgroups described earlier, neuropsychologically normal, deteriorated, and compromised, across psychotic disorders and illness stage. The different trajectories model makes several testable predictions, with respect to the frequency of cognitive subgroups. First, consistent with relatively greater neurodevelopmental involvement in schizophrenia, the proportion of neuropsychologically compromised patients should be higher in schizophrenia than psychotic bipolar disorder. Second, consistent with a static course following illness onset, the proportion of neuropsychologically deteriorated patients should be similar in the early and chronic stages of schizophrenia. Finally, the neuroprogressive model of bipolar disorder predicts that the proportion of neuropsychologically deteriorated patients should be higher in the chronic than early stage of the illness.

\section{METHODS}

\subsection{Participants}

Data from 671 individuals (410 patients with a psychotic disorder, 261 healthy subjects), who participated in a data repository study (clinicaltrials.gov; NCT00762866), were included in this investigation. The psychosis sample included 298 individuals with a schizophrenia spectrum disorder (i.e. schizophreniform disorder, schizophrenia, schizoaffective disorder) and 112 participants with bipolar disorder, type I, with psychotic features (i.e. "psychotic bipolar disorder"). Using the same criteria as described previously by our group (Woodward and Heckers, 2016), 178 patients (127 schizophrenia, 51 psychotic 
bipolar disorder) were classified as early stage (i.e. within 2 years of psychosis onset, regardless of mood disorder history). Demographic data for the healthy controls and psychosis patients, broken down by diagnosis and illness stage, are presented in Table 1. Psychosis patients were recruited through the Vanderbilt Psychotic Disorders Program at Vanderbilt University Medical Center. Healthy individuals were recruited from the local community via advertisement and word-of-mouth. The study was approved by the Vanderbilt University Institutional Review Board and all study subjects provided written informed consent prior to participating in the study.

The Structured Clinical Interview for DSM-IV Disorders (SCID; First M.B., S.R.L., Gibbon M., 2002) was administered to all study participants by a trained rater to confirm diagnoses in patients and rule out psychopathology in healthy individuals. Additionally, clinically relevant dimensions of psychopathology, including positive and negative symptoms of psychosis, mania, and depression were assessed in patients with the Positive and Negative Syndrome Scale (PANSS; Kay et al., 1987), Young Mania Rating Scale (YMRS; Young et al., 1978), and Hamilton Depression rating scale (HAM-D; Hamilton, 1960), respectively. Exclusion criteria for all participants included significant head trauma, major neurological or medical illness (e.g. cancer), pregnancy, substance abuse or dependence within the past month at the time of study enrollment, and premorbid IQ less than 70 as estimated by the Wechsler Test of Adult Reading (WTAR; Wechsler, 2001). Additional exclusion criteria for healthy control participants included absence of past or present psychiatric disorder, and absence of a first-degree relative with a psychotic disorder.

\subsection{Neuropsychological Testing}

The Wechsler Test of Adult Reading (WTAR; Wechsler, 2001) and Screen for Cognitive Impairment In Psychiatry (SCIP; Purdon, 2005) were administered to provide measures of estimated premorbid intellectual ability and neuropsychological functioning, respectively. Briefly, the SCIP consists of five subtests: 1) verbal list learning-immediate which entails three repetitions of a 10-item word list; 2) a verbal working memory test similar to the Auditory Consonant Trigrams test (Stuss et al., 1987); 3) phonemic verbal fluency; 4) a graphomotor test of psychomotor processing speed modeled after the Wechsler Adult Intelligence Scales Digit-Symbol/Coding test (Wechsler, 1997); and 5) a delayed recall trial of the verbal list learning test. SCIP subtest raw scores were converted to Z-scores using published normative data (Purdon, 2005).

\subsection{Statistical Analysis}

We used our relatively large sample of healthy individuals as normative data to correct for the effects of key demographic variables on cognitive performance; a commonly used approach in clinical neuropsychology (Casaletto and Heaton, 2017). Specifically, prior to examining group differences in cognition, SCIP subtest Z-scores were adjusted for age, sex, and race by: 1) regressing SCIP subtest Z-scores on age, sex, and race in the healthy sample $(\mathrm{n}=261) ; 2)$ applying the subsequent regression equations to derive predicted subtest $\mathrm{Z}$ scores in all subjects; and 3) standardizing the residual (i.e. predicted minus actual) subtest Z-scores using the healthy sample as normative data (see Supplemental Material for results of regression analyses). The age, sex, and race corrected subtest Z-scores were averaged to 
create a composite SCIP Z-score. SCIP Composite and subtest Z-scores served as dependent variables in the following analysis.

First, to test the hypothesis that cognitive impairment is more severe in schizophrenia than bipolar disorder in the early stage of psychosis, one-way ANOVAs were performed with SCIP Composite and subtest Z-scores as the dependent variables and diagnosis (healthy subjects, schizophrenia, psychotic bipolar disorder) as the independent variable. Analyses were performed with SPSS statistical software, with $a=.05$ for the composite score and a Bonferroni-corrected $a=.01(.05 / 5)$ for the subtests. Significant ANOVAs were followed up with post-hoc contrasts.

Next, to test the hypothesis that cognitive impairment in psychosis varies as a function of both diagnosis and illness stage, a two-way ANOVA was performed on SCIP Composite and subtest Z-scores with diagnosis (schizophrenia, psychotic bipolar disorder) and illness stage (early stage, chronic) as independent variables. Healthy subjects were excluded from this analysis to test the critical diagnosis by illness stage interaction. An $a=.05$ was used for the composite score and $\alpha=.01(.05 / 5)$ for the subtests

Finally, psychosis patients were divided into neuropsychologically normal, deteriorated, and compromised subgroups using the same method described previously by our group and others (Czepielewski et al., 2016; Weickert et al., 2000; Woodward and Heckers, 2015). Briefly, patients were classified as neuropsychologically normal if: 1) their estimated premorbid intellectual functioning from the WTAR was above the $10^{\text {th }}$ percentile of the healthy subjects' distribution; and 2) their current cognitive ability (i.e. SCIP Composite Zscore) was consistent with expectations based on their estimated premorbid intellect. The latter was tested by adding WTAR estimated premorbid IQ to the SCIP regression models described earlier and calculating the discrepancy between their age, sex, race, and WTAR IQ predicted and actual SCIP Composite Z-score. Psychosis patients with a predicted vs. actual SCIP Composite Z-score above the $10^{\text {th }}$ percentile of the healthy subjects' distribution were considered neuropsychologically normal. The remaining patients, which were considered cognitively impaired, were classified as deteriorated if their estimated premorbid IQ was above the $10^{\text {th }}$ percentile and the discrepancy between their actual and predicted SCIP Composite Z-score was below the $10^{\text {th }}$ percentile of the healthy subjects' distribution, or compromised if their estimated premorbid IQ was below the $10^{\text {th }}$ percentile. We selected this method for defining cognitive subgroups for several reasons. First, it is consistent with the discrepancy analysis approach used in clinical neuropsychology for identifying differential deficits. Second, it has been used in prior studies for dissecting heterogeneity of cognitive impairment in psychotic disorders (Weickert et al., 2000). Finally, findings from neuroimaging support its validity (Czepielewski et al., 2016; Weinberg et al., 2016; Woodward and Heckers, 2015).

Chi-square tests $(\alpha=.05)$ with post hoc contrasts calculated using the adjusted residuals method were used to test the following specific hypotheses: 1) the frequency of neuropsychologically compromised patients is higher in schizophrenia compared to psychotic bipolar disorder; 2) within schizophrenia, the proportion of neuropsychologically deteriorated patients does not differ between early stage and chronic patients; and 3) within 
psychotic bipolar disorder, the frequency of deteriorated patients is higher in the chronic than early stage of illness.

\section{RESULTS}

\subsection{Neuropsychological Functioning in Early Stage Schizophrenia and Psychotic Bipolar Disorder}

Composite and sub-test SCIP Z-scores in healthy subjects and early stage schizophrenia and bipolar disorder are presented in Figure 1. SCIP Composite score differed significantly across groups $(\mathrm{F}(2,436)=85.81, \mathrm{p}<.001)$. Post hoc contrasts were consistent with our hypothesis that while cognitive function is impaired in both schizophrenia $(\mathrm{p}<.001)$ and psychotic bipolar disorder ( $\mathrm{p}<.001)$, the severity of impairment is greater in schizophrenia compared to psychotic bipolar disorder ( $\mathrm{p}<.001)$. Significant group effects were observed on all SCIP subtests (all $\mathrm{F}(2,436)>12.32$, $\mathrm{p}<.001$ ). A similar pattern as that detected for SCIP Composite score (i.e. healthy subjects>psychotic bipolar disorder>schizophrenia) was observed for verbal list learning-immediate recall, working memory, and processing speed. A different pattern of results was observed for verbal fluency and verbal list learningdelayed recall; verbal fluency was impaired in schizophrenia but not psychotic bipolar disorder, whereas impairment in delayed verbal recall was similar in schizophrenia and psychotic bipolar disorder (see Supplemental Material for complete statistical results).

Although we used a large sample of healthy subjects as normative data to correct for demographic variables, we complemented the primary analysis described above with a sensitivity analysis to ensure differences in sample sizes and demographics did not affect the results (see Supplemental Material). Briefly, early stage schizophrenia and psychotic bipolar disorder patients, and healthy controls ( $\mathrm{n}=44$ per group), matched 1:1:1 based on age $( \pm 3$ years), sex, race, and parental education ( \pm 3 years), were extracted from the early stage patient cohort and healthy subjects and compared on unadjusted SCIP Composite and subtest scores. As shown in the Supplemental Material, results of this analysis were virtually identical to those reported above: overall cognitive function was impaired in both schizophrenia and psychotic bipolar disorder, relative to healthy subjects, and the degree of impairment was more severe in schizophrenia. Moreover, the same gradient of performance (i.e. healthy subjects>psychotic bipolar disorder>schizophrenia) was observed on SCIP subtests, except for verbal fluency, which was preserved in bipolar disorder, and delayed verbal recall, which was equally impaired in schizophrenia and psychotic bipolar disorder.

\subsection{Diagnosis and IIIness Stage Effects on Neuropsychological Functioning in Psychosis}

SCIP Composite and subtest Z-scores are presented in Figure 2 and the Supplemental Material. The two-way ANOVA of SCIP Composite Z-score revealed main effects of diagnosis $(\mathrm{F}(1,406)=22.51, \mathrm{p}<.001)$, schizophrenia patients were more impaired than psychotic bipolar disorder, and illness stage $(\mathrm{F}(1,406)=14.35, \mathrm{p}<.001)$, cognitive function was more impaired in chronic than early stage patients. Notably, in contrast to our hypothesis, the interaction between diagnosis and illness stage was not significant $(\mathrm{F}(1,406)=0.21, \mathrm{p}=.648)$. 
Similar results were obtained for most of the SCIP subtest scores. Main effects of diagnosis and illness stage were detected for verbal list learning-immediate $(\mathrm{F}(1,406)=11.52, \mathrm{p}=.001$; $\mathrm{F}(1,406)=12.15, \mathrm{p}=.001)$, working memory $(\mathrm{F}(1,406)=18.05$, $\mathrm{p}<.001 ; \mathrm{F}(1,406)=9.34$, $\mathrm{p}=$. $002)$, processing speed $(\mathrm{F}(1,406)=12.30, \mathrm{p}=.001 ; \mathrm{F}(1,406)=4.77, \mathrm{p}=.030)$, and verbal fluency $(\mathrm{F}(1,406)=6.54, \mathrm{p}=.011 ; \mathrm{F}(1,406)=14.45, \mathrm{p}<.001)$. A main effect of diagnosis $(\mathrm{F}(1,406)=7.34, \mathrm{p}=.007)$, but not illness stage $(\mathrm{F}(1,406)=0.72, \mathrm{p}=.398)$ was observed for verbal list learning-delayed recall. The diagnosis by illness stage interaction was not significant for any subtest; although, verbal fluency reached trend significance level $(\mathrm{F}(1,406)=3.39, \mathrm{p}=.066)$ due to the fact that verbal fluency was more impaired in schizophrenia than bipolar disorder in early stage $(\mathrm{t}(176)=2.99, \mathrm{p}=.003)$, but not chronic patients $(\mathrm{t}(230)=0.53, \mathrm{p}=.596)$.

\subsection{Neuropsychological Subgroups in Psychosis}

The frequencies of cognitive subgroups across the entire cohort of patients and within each diagnostic group are presented in Figure 3. The chi-square testing for different frequencies of neuropsychological subgroups in schizophrenia and bipolar disorder was significant $\left(\chi_{(2)}^{2}=15.54, p<.001\right)$. Post hoc contrasts confirmed our hypothesis that the proportion of neuropsychologically compromised patients is higher in schizophrenia compared to psychotic bipolar disorder $\left(36.9 \%\right.$ vs. $\left.22.3 \% ; \chi^{2}{ }_{(1)}=7.84, p<.005\right)$ and revealed that the proportion of neuropsychologically normal patients is higher in psychotic bipolar disorder compared to schizophrenia ( $46.4 \%$ vs. $\left.26.8 \% ; \chi^{2}{ }_{(1)}=14.29, p<.001\right)$. The proportion of neuropsychologically deteriorated patients was similar in schizophrenia and psychotic bipolar disorder $\left(36.2 \%\right.$ vs. $\left.31.3 \% ; \chi^{2}{ }_{(1)}=0.88, p=.345\right)$.

Within psychotic disorders, the proportions of neuropsychological subgroups differed as a function of illness stage in both schizophrenia $\left(\chi_{(2)}^{2}=7.99, \mathrm{p}=.018\right)$ and bipolar disorder $\left(\chi_{(2)}^{2}=7.79, p=.020\right)$. Consistent with our hypothesis, the proportion of neuropsychologically deteriorated patients did not differ between early stage and chronic schizophrenia (35.4\% vs. $\left.36.8 \% ; \chi^{2}{ }_{(1)}=0.06, p=.802\right)$; although the chronic cohort included relatively more compromised patients $\left(42.1 \%\right.$ vs. $29.9 \%$; $\left.\chi_{(1)}^{2}=4.64, p=.031\right)$ and fewer neuropsychologically normal patients $\left(21.1 \%\right.$ vs.34.6\%; $\left.\chi_{(1)}^{2}=6.85, \mathrm{p}=.009\right)$ compared to the early stage cohort. In psychotic bipolar disorder, our hypothesis that the proportion of neuropsychologically deteriorated patients would be higher in the chronic stage of the illness was not supported $\left(37.7 \%\right.$ vs. $\left.23.5 \% ; \chi^{2}(1)=2.60, p=.107\right)$. Additional post hoc contrasts within the psychotic bipolar disorder group indicated that the proportion of neuropsychologically normal patients was lower in chronic than early stage patients (34.4\% vs. $\left.60.8 \% ; \chi_{(1)}^{2}=7.76, p=.005\right)$. Although the proportion of neuropsychologically compromised patients was higher in chronic than early stage bipolar disorder patients, the difference was not significant $\left(27.9 \%\right.$ vs $\left.15.7 \% ; \chi^{2}{ }_{(1)}=2.38, p=.123\right)$.

\section{DISCUSSION}

The current study examined neuropsychological functioning in a large sample of individuals with schizophrenia and psychotic bipolar disorder and was motivated in large part to better understand the trajectories of cognitive impairment in psychosis. Specifically, we tested 
several key predictions of the different trajectories hypothesis which posits, broadly, that cognitive impairment is largely neurodevelopmental and static in schizophrenia, whereas bipolar disorder is characterized by relatively normal cognitive development and progressive decline following illness onset (Berk et al., 2011; Fries et al., 2012; Lewandowski et al., 2011; Parellada et al., 2017).

First, we tested the hypothesis that, consistent with greater neurodevelopmental involvement in schizophrenia, neuropsychological impairment in the early stage of psychosis is more severe in schizophrenia compared to psychotic bipolar disorder. This hypothesis was confirmed; overall neuropsychological functioning and performance in specific cognitive domains, including immediate verbal recall, working memory, processing speed, and verbal fluency was more impaired in schizophrenia. The results are generally consistent with prior reports of greater impairment in overall cognitive function in schizophrenia compared to bipolar disorder (Barrett et al., 2009; Dickerson et al., 2011; Hill et al., 2009; Mojtabai et al., 2000; Zanelli et al., 2010). Our findings also further clarify neuropsychological impairment in psychotic bipolar disorder. Specifically, some studies have found that neuropsychological impairment in psychotic bipolar disorder is limited to specific cognitive domains (e.g. Zanelli et al., 2010), whereas others report generalized impairment encompassing most cognitive domains (Barrett et al., 2009; Dickerson et al., 2011; Hill et al., 2009). Our results showing that, relative to healthy subjects, early stage psychotic bipolar patients exhibit impairment in most cognitive domains, including verbal learning and memory, working memory, and processing speed, are consistent with generalized impairment.

Following the analysis of early stage patients, we examined the impact of diagnosis and illness stage on neuropsychological functioning in our entire cohort of psychosis patients. We tested the hypothesis that there is an interaction between diagnosis and illness stage, a key prediction of the different cognitive trajectories model. None of the interaction effects reached significance even in our large, relatively well-powered sample. In contrast, main effects of diagnosis and illness stage were observed for overall cognitive function and most cognitive subtests. Specifically, schizophrenia patients demonstrated greater cognitive impairment than psychotic bipolar patients and impairment was more severe in chronic than early stage patients. The former finding is consistent with the previous finding that bipolar disorder patients were less impaired than schizophrenia patients on the Spanish version of the SCIP (Gómez-Benito et al., 2013). As discussed below, interpretation of the main effect of illness stage is complicated by the cross-sectional study design. However, the main effect of diagnosis recapitulates findings in early stage patients and the lack of robust interaction effects argues against differential effects of illness duration on cognition across psychotic disorders.

Finally, we examined the prevalence of cognitive subgroups in our combined sample of schizophrenia and psychotic bipolar patients. This analysis was undertaken to determine the prevalence of cognitive subgroups in psychotic bipolar disorder, which has received relatively little attention, and to test several predictions of the different trajectories model of cognitive impairment in psychosis. Consistent with the hypothesis of greater neurodevelopmental involvement in schizophrenia and relative sparing of premorbid cognition in bipolar disorder, the relative proportion of neuropsychologically compromised 
patients was higher in schizophrenia, whereas more psychotic bipolar patients were classified as neuropsychologically normal. Interestingly, the proportion of neuropsychologically deteriorated patients was similar in schizophrenia and psychotic bipolar disorder (36.2\% vs. $31.3 \%$, respectively). Within schizophrenia there was little difference between early and chronic stages in the prevalence of neuropsychologically deteriorated patients ( $35.4 \%$ vs. $36.8 \%$ ). The prevalence of neuropsychologically deteriorated patients also did not differ significantly between illness stage cohorts in psychotic bipolar disorder. The findings dovetail nicely with longitudinal studies showing that cognitive function deteriorates prior to illness onset, but remains relatively stable following illness onset (Fuller et al., 2002; Hoff et al., 2005; Reichenberg et al., 2010). However, this interpretation is tempered by main effects of illness stage observed in the analyses and differences between early stage and chronic groups in the proportion of cognitively normal individuals. Both findings raise the possibility of additional cognitive decline after illness onset, but, as discussed below, may also reflect limitations of our crosssectional study design.

As with any study, the current investigation has several limitations that must be considered when interpreting the results. The use of cross-sectional data to examine illness stage and its potential interaction with diagnosis is a primary limitation of our study. Specifically, the main effect of illness stage on cognitive impairment observed in the analysis of our entire patient cohort should be interpreted cautiously given the vulnerability of cross-sectional designs to cohort effects due to ascertainment bias. Indeed, the greater proportion of neuropsychologically compromised patients in both illnesses at chronic stage suggests that the main effect of illness stage may have been driven, at least in part, by cohort effects. Longitudinal studies have found that symptomatic recovery may be associated with better cognitive functioning (Kotov et al., 2017; Lepage et al., 2014; Rund et al., 2015; Trampush et al., 2015). Consequently, differences across illness stages in the proportions of neuropsychologically normal and compromised patients may result, at least in part, from ascertainment bias towards including a greater proportion of individuals with a persistent, severe clinical course in our chronic samples. It is worth reiterating, however, that the main purpose of analyzing our total patient sample was to test for the presence of diagnosis by illness stage interactions. It is unlikely that cohort effects would increase (or decrease) the likelihood of detecting an interaction effect unless there was a bias towards recruiting more severely impaired patients from one diagnostic group specifically. Moreover, the presence of such bias would increase the likelihood of detecting a "false positive" illness stage by diagnosis interaction — we found very little evidence of diagnosis by illness stage interactions.

Another potential limitation is our method for determining cognitive subgroups which relies on estimating premorbid intellect based on cross-sectional data (i.e. single word reading ability). While findings from longitudinal studies support the validity of word reading tests to assess premorbid intellect in healthy individuals (Dykiert and Deary, 2013), neurological disorders (Bright et al., 2002) and psychotic disorders (Harvey et al., 2006, 2000; Kondel et al., 2003; Morrison et al., 2000), longitudinal designs are the gold-standard for examining the effects of illness duration and determining premorbid cognitive function. However, 
collecting longitudinal cognitive data across many years, likely several decades given the nature of the hypotheses, is a challenge.

In conclusion, the present study examined cognitive impairment in a reasonably large sample of early and chronic stage schizophrenia and psychotic bipolar patients. Our analysis of early stage patients revealed that cognitive impairment is more severe in schizophrenia than psychotic bipolar disorder. Moreover, cognitive subgroup analyses found that the proportion of neuropsychologically compromised patients was higher in schizophrenia. Both findings are consistent with etiological models implicating greater neurodevelopmental compromise in schizophrenia. This does not imply that cognitive development is entirely normal in psychotic bipolar disorder. To the contrary, early stage psychotic bipolar patients exhibited mild generalized cognitive impairment, on the order of 0.5 standard deviations below normal, and a modest proportion (22.3\%) of psychotic bipolar patients were classified as neuropsychologically compromised. In contrast, we found very little evidence that the trajectories of cognitive dysfunction following illness onset differ between schizophrenia and psychotic bipolar disorder. No significant diagnosis by illness stage interactions were detected, the proportion of neuropsychologically deteriorated patients was not higher in psychotic bipolar disorder compared to schizophrenia, and, within psychotic bipolar disorder, the proportion of neuropsychologically deteriorated patients did not significantly differ between early stage and chronic patients. Overall our results indicate that while there is relatively greater neurodevelopmental involvement in schizophrenia, psychotic bipolar disorder and schizophrenia cannot be dichotomized into purely neuroprogressive and neurodevelopmental illness trajectories - there is evidence of both processes in each disorder.

\section{Supplementary Material}

Refer to Web version on PubMed Central for supplementary material.

\section{Acknowledgements}

The authors would like to thank Erin Brosey, Molly Boyce, Yasmeen Iqbal, Sam Luce, Katherine Seldin, Margaret Quinn, and Austin Woolard with assistance in collection of data.

Funding

This research was supported by the Charlotte and Donald Test Fund, and National Institute of Mental Health (NIMH) grants R01 MH070560 (SH) and R01 MH102266 (NDW). Dr. Blackford's time was partially supported by the Jack Martin MD Research Professorship in Psychopharmacology (awarded to JUB) and a Merit Award (CX001226) from the US Department of Veterans Affairs.

\section{References}

Badcock JC, Dragović M, Waters FAV, Jablensky A, 2005 Dimensions of intelligence in schizophrenia: evidence from patients with preserved, deteriorated and compromised intellect. J. Psychiatr. Res. 39(1), 11-9. [PubMed: 15504419]

Barrett SL, Mulholland CC, Cooper SJ, Rushe TM, 2009 Patterns of neurocognitive impairment in first-episode bipolar disorder and schizophrenia. Br. J. Psychiatry (195), 67-72. [PubMed: 19567899]

Berk M, Kapczinski F, Andreazza AC, Dean OM, Giorlando F, Maes M, Yücel M, Gama CS, Dodd S, Dean B, Magalhães PVS, Amminger P, McGorry P, Malhi GS, 2011 Pathways underlying 
neuroprogression in bipolar disorder: Focus on inflammation, oxidative stress and neurotrophic factors. Neurosci. Biobehav. Rev 35(3), 804-817. [PubMed: 20934453]

Bora E, Yucel M, Pantelis C, 2009 Cognitive functioning in schizophrenia, schizoaffective disorder and affective psychoses: Meta-analytic study. Br. J. Psychiatry 195(6), 475-482. [PubMed: 19949193]

Bright P, Jaldow E, Kopelman MD, 2002 The National Adult Reading Test as a measure of premorbid intelligence: a comparison with estimates derived from demographic variables. J. Int. Neuropsychol. Soc. 8(6), 847-54. [PubMed: 12240749]

Casaletto KB, Heaton RK, 2017 Neuropsychological Assessment: Past and Future. J. Int. Neuropsychol. Soc. 23(9-10), 778-790. [PubMed: 29198281]

Czepielewski LS, Wang L, Gama CS, Barch DM, 2016 The Relationship of Intellectual Functioning and Cognitive Performance to Brain Structure in Schizophrenia. Schizophr. Bull. 43(2), sbw090.

Dickerson F, Stallings C, Vaughan C, Origoni A, Khushalani S, Dickinson D, Medoff D, 2011 Cognitive Functioning in Recent Onset Psychosis. J. Nerv. Ment. Dis 199(6), 367-371. [PubMed: 21629013]

Dykiert D, Deary IJ, 2013 Retrospective validation of WTAR and NART scores as estimators of prior cognitive ability using the Lothian Birth Cohort 1936. Psychol. Assess. 25(4), 1361-1366. [PubMed: 23815111]

First MB, S. RL, Gibbon M, W.J. BW, 2002 Structured Clinical Interview for DSM-IV-TR Axis I Disorders, Research Version, Patient Edition (SCID-I/P) Biometrics Research, New York State Psychiatric Institute, New York, NY.

Fries GR, Pfaffenseller B, Stertz L, Paz AVC, Dargél AA, Kunz M, Kapczinski F, 2012 Staging and Neuroprogression in Bipolar Disorder. Curr. Psychiatry Rep 14(6), 667-675. [PubMed: 23090632]

Fuller R, Nopoulos P, Arndt S, O'Leary D, Ho B-C, Andreasen NC, 2002 Longitudinal Assessment of Premorbid Cognitive Functioning in Patients With Schizophrenia Through Examination of Standardized Scholastic Test Performance. Am. J. Psychiatry 159(7), 1183-1189. [PubMed: 12091197]

Gold S, Arndt S, Nopoulos P, O’Leary DS, Andreasen NC, 1999 Longitudinal study of cognitive function in first-episode and recent-onset schizophrenia. Am. J. Psychiatry 156(9), 1342-8. [PubMed: 10484943]

Gómez-Benito J, Guilera G, Pino Ó, Rojo E, Tabarés-Seisdedos R, Safont G, Martínez-Arán A, Franco M, Cuesta MJ, Crespo-Facorro B, Bernardo M, Vieta E, Purdon SE, Mesa F, Rejas J, Spanish Working Group in Cognitive Function, 2013 The screen for cognitive impairment in psychiatry: diagnostic-specific standardization in psychiatric ill patients. BMC Psychiatry 13, 127. [PubMed: 23648193]

Hamilton M, 1960 A rating scale for depression. J. Neurol. Neurosurg. Psychiatry 23(1), 56-62. [PubMed: 14399272]

Harvey PD, Friedman JI, Bowie C, Reichenberg A, McGurk SR, Parrella M, White L, Davis KL, 2006 Validity and stability of performance-based estimates of premorbid educational functioning in older patients with schizophrenia. J. Clin. Exp. Neuropsychol. 28(2), 178-92. [PubMed: 16484092]

Harvey PD, Moriarty PJ, Friedman JI, White L, Parrella M, Mohs RC, Davis KL, 2000 Differential preservation of cognitive functions in geriatric patients with lifelong chronic schizophrenia: less impairment in reading compared with other skill areas. Biol. Psychiatry 47(11), 962-8. [PubMed: 10838064]

Hill SK, Reilly JL, Harris MSH, Rosen C, Marvin RW, Deleon O, Sweeney JA, 2009 A comparison of neuropsychological dysfunction in first-episode psychosis patients with unipolar depression, bipolar disorder, and schizophrenia. Schizophr. Res. 113(2-3), 167-75. [PubMed: 19450952]

Hoff AL, Svetina C, Shields G, Stewart J, DeLisi LE, 2005 Ten year longitudinal study of neuropsychological functioning subsequent to a first episode of schizophrenia. Schizophr. Res. 78(1), 27-34. [PubMed: 15964177]

Kay SR, Fiszbein A, Opler LA, 1987 The positive and negative syndrome scale (PANSS) for schizophrenia. Schizophr. Bull. 13(2), 261-76. [PubMed: 3616518] 
Kondel TK, Mortimer AM, Leeson VC, Laws KR, Hirsch SR, 2003 Intellectual Differences Between Schizophrenic Patients and Normal Controls Across the Adult Lifespan. J. Clin. Exp. Neuropsychol 25(8), 1045-1056. [PubMed: 14566578]

Kotov R, Fochtmann L, Li K, Tanenberg-Karant M, Constantino EA, Rubinstein J, Perlman G, Velthorst E, Fett A-KJ, Carlson G, Bromet EJ, 2017 Declining Clinical Course of Psychotic Disorders Over the Two Decades Following First Hospitalization: Evidence From the Suffolk County Mental Health Project. Am. J. Psychiatry 174(11), 1064-1074. [PubMed: 28774193]

Lepage M, Bodnar M, Bowie CR, 2014 Neurocognition: clinical and functional outcomes in schizophrenia. Can. J. Psychiatry 59(1), 5-12. [PubMed: 24444318]

Lewandowski KE, Cohen BM, Öngur D, 2011 Evolution of neuropsychological dysfunction during the course of schizophrenia and bipolar disorder. Psychol. Med 41(02), 225-241. [PubMed: 20836900]

Mojtabai R, Bromet EJ, Harvey PD, Carlson GA, Craig TJ, Fennig S, 2000 Neuropsychological Differences Between First-Admission Schizophrenia and Psychotic Affective Disorders. Am. J. Psychiatry 157(9), 1453-1460. [PubMed: 10964862]

Morrison G, Sharkey V, Allardyce J, Kelly RC, McCreadie RG, 2000 Nithsdale schizophrenia surveys 21: a longitudinal study of National Adult Reading Test stability. Psychol. Med 30(3), 717-20. [PubMed: 10883725]

Parellada M, Gomez-Vallejo S, Burdeus M, Arango C, 2017 Developmental Differences Between Schizophrenia and Bipolar Disorder. Schizophr. Bull 43(6), 1176-1189. [PubMed: 29045744]

Purdon S, 2005 The Screen for Cognitive Impairment in Psychiatry (SCIP): Administration Manual and Normative Data PNL Inc, Alberta, Canada.

Reichenberg A, Caspi A, Harrington H, Houts R, Keefe RSE, Murray RM, Poulton R, Moffitt TE, 2010 Static and Dynamic Cognitive Deficits in Childhood Preceding Adult Schizophrenia: A 30Year Study. Am. J. Psychiatry 167(2), 160-169. [PubMed: 20048021]

Reichenberg A, Harvey PD, Bowie CR, Mojtabai R, Rabinowitz J, Heaton RK, Bromet E, 2009 Neuropsychological function and dysfunction in schizophrenia and psychotic affective disorders. Schizophr. Bull 35(5), 1022-9. [PubMed: 18495643]

Rund BR, Barder HE, Evensen J, Haahr U, Hegelstad W ten V, Joa I, Johannessen JO, Langeveld J, Larsen TK, Melle I, Opjordsmoen S, Røssberg JI, Simonsen E, Sundet K, Vaglum P, McGlashan T, Friis S, 2015 Neurocognition and Duration of Psychosis: A 10-year Follow-up of First-Episode Patients. Schizophr. Bull 42(1), sbv083.

Seidman LJ, Kremen WS, Koren D, Faraone SV, Goldstein JM, Tsuang MT, 2002 A comparative profile analysis of neuropsychological functioning in patients with schizophrenia and bipolar psychoses. Schizophr. Res 53(1-2), 31-44. [PubMed: 11728836]

Simonsen C, Sundet K, Vaskinn A, Birkenaes AB, Engh JA, Faerden A, Jónsdóttir H, Ringen PA, Opjordsmoen S, Melle I, Friis S, Andreassen OA, 2011 Neurocognitive dysfunction in bipolar and schizophrenia spectrum disorders depends on history of psychosis rather than diagnostic group. Schizophr. Bull 37(1), 73-83. [PubMed: 19443616]

Stuss DT, Stethem LL, Poirier CA, 1987 Comparison of three tests of attention and rapid information processing across six age groups. Clin. Neuropsychol 1(2), 139-152.

Trampush JW, Lencz T, DeRosse P, John M, Gallego JA, Petrides G, Hassoun Y, Zhang J-P, Addington J, Kellner CH, Tohen M, Burdick KE, Goldberg TE, Kane JM, Robinson DG, Malhotra AK, 2015 Relationship of Cognition to Clinical Response in First-Episode Schizophrenia Spectrum Disorders. Schizophr. Bull 41(6), 1237-1247. [PubMed: 26409223]

Wechsler D, 2001 Wechsler Test of Adult Reading Pearson Education, San Antonio, TX.

Wechsler D, 1997 Wechsler Adult Intelligence Scale-3rd Edition Harcourt Assessment, San Antonio, TX.

Weickert TW, Goldberg TE, Gold JM, Bigelow LB, Egan MF, Weinberger DR, 2000 Cognitive Impairments in Patients With Schizophrenia Displaying Preserved and Compromised Intellect. Arch. Gen. Psychiatry 57(9), 907. [PubMed: 10986554]

Weinberg D, Lenroot R, Jacomb I, Allen K, Bruggemann J, Wells R, Balzan R, Liu D, Galletly C, Catts SV, Weickert CS, Weickert TW, 2016 Cognitive Subtypes of Schizophrenia Characterized by 
Differential Brain Volumetric Reductions and Cognitive Decline. JAMA Psychiatry 73(12), 1251. [PubMed: 27829096]

Woodward ND, 2016 The course of neuropsychological impairment and brain structure abnormalities in psychotic disorders. Neurosci. Res 102, 39-46. [PubMed: 25152315]

Woodward ND, Heckers S, 2016 Mapping Thalamocortical Functional Connectivity in Chronic and Early Stages of Psychotic Disorders. Biol. Psychiatry 79(12), 1016-1025. [PubMed: 26248537]

Woodward ND, Heckers S, 2015 Brain Structure in Neuropsychologically Defined Subgroups of Schizophrenia and Psychotic Bipolar Disorder. Schizophr. Bull 41(6), 1349-1359. [PubMed: 25904725]

Young RC, Biggs JT, Ziegler VE, Meyer DA, 1978 A rating scale for mania: reliability, validity and sensitivity. Br. J. Psychiatry 133, 429-35. [PubMed: 728692]

Zanelli J, Reichenberg A, Morgan K, Fearon P, Kravariti E, Dazzan P, Morgan C, Zanelli C, Demjaha A, Jones PB, Doody GA, Kapur S, Murray RM, 2010 Specific and Generalized

Neuropsychological Deficits: A Comparison of Patients With Various First-Episode Psychosis Presentations. Am. J. Psychiatry 167(1), 78-85. [PubMed: 19952077]

Zubieta J-K, Huguelet P, O’Neil RL, Giordani BJ, 2001 Cognitive function in euthymic Bipolar I Disorder. Psychiatry Res 102(1), 9-20. [PubMed: 11368835] 


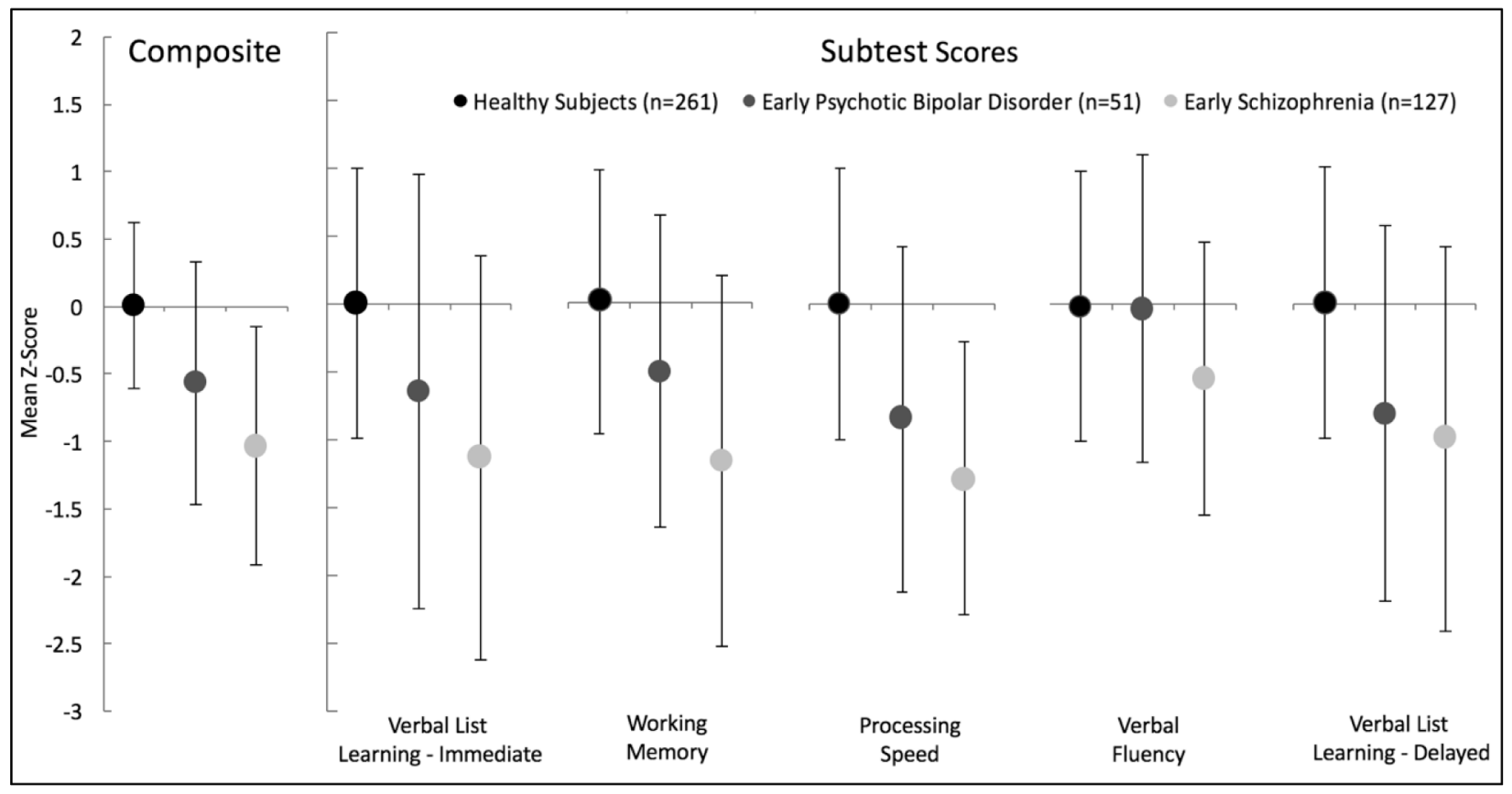

Figure 1.

Neuropsychological performance in early stage psychosis. SCIP Composite score differed significantly across groups $(\mathrm{p}<.001)$. Post hoc contrasts revealed that both schizophrenia and psychotic bipolar disorder were impaired compared to healthy subjects (p's<.001), and severity of impairment is greater in schizophrenia compared to psychotic bipolar disorder $(\mathrm{p}<.001)$. Significant group effects were observed on all SCIP subtests ( $\mathrm{p}$ 's<.001). A similar pattern as that detected for SCIP Composite score (i.e. healthy subjects>psychotic bipolar disorder>schizophrenia) was observed for verbal list learning-immediate recall, working memory, and processing speed. For verbal fluency, only schizophrenia was impaired compared to healthy controls. For delayed verbal recall, both schizophrenia and psychotic bipolar disorder were impaired compared to healthy subjects, but were not different from each other. Statistical results are described in detail in the text and Supplemental Material. Error bars indicate standard deviation of the mean. 


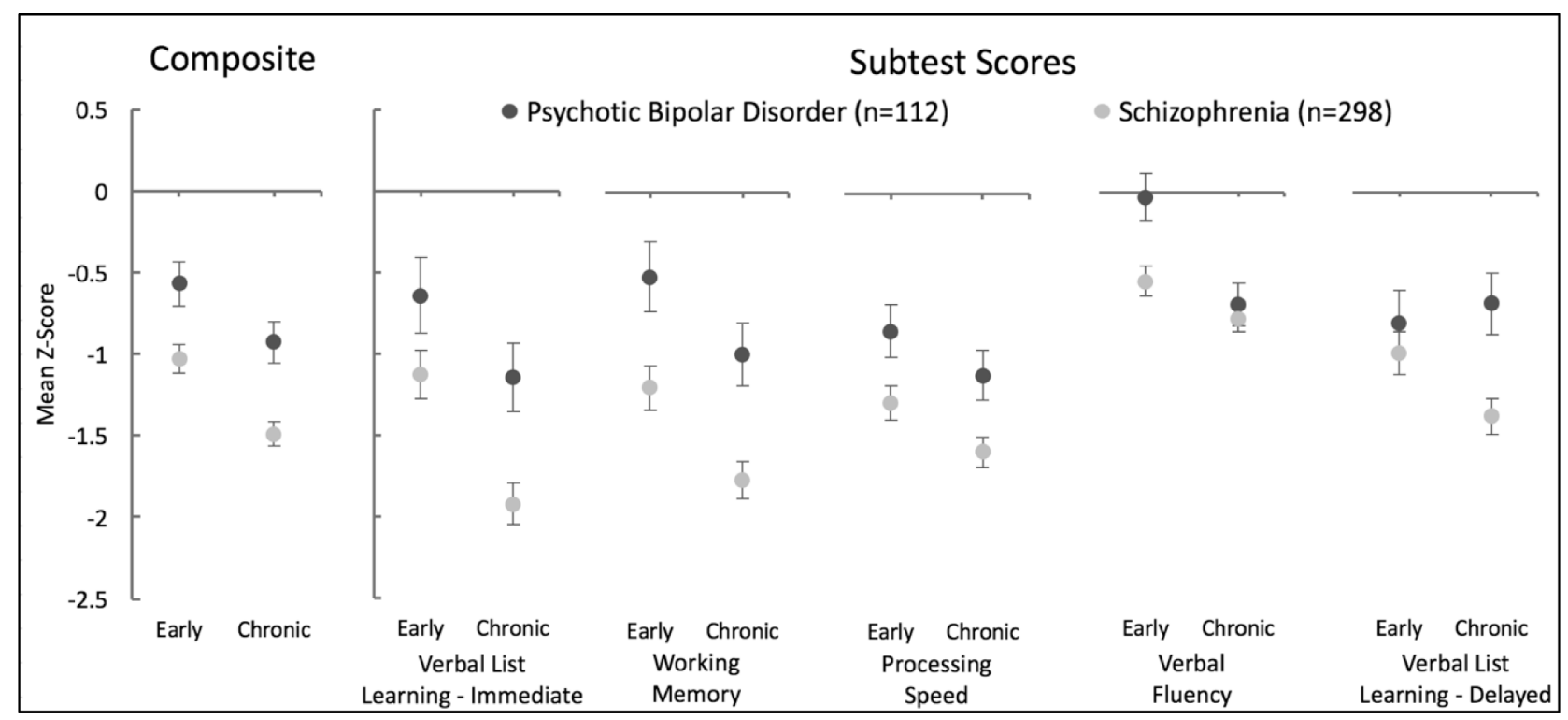

Figure 2.

Effects of diagnosis and illness stage on neuropsychological performance. The two-way ANOVA of SCIP Composite Z-score revealed main effects of diagnosis $(\mathrm{p}<.001)$ and illness stage $(\mathrm{p}<.001)$. The interaction between diagnosis and illness stage was not significant $(\mathrm{p}=$. 648). Main effects of diagnosis and illness stage reached significance for verbal list learningimmediate, working memory, processing speed, and verbal fluency. A main effect of diagnosis, but not illness stage was observed for verbal list learning-delayed recall. The diagnosis by illness stage interaction was not significant for any subtest, with the exception of verbal fluency which reached trend significance level $(p=.066)$ due to the fact that verbal fluency was more impaired in schizophrenia than bipolar disorder in early stage $(\mathrm{p}=.003)$, but not chronic patients ( $\mathrm{p}=.596)$. Error bars indicate standard error of the mean. Statistics are presented in detail in the Supplemental Material. 


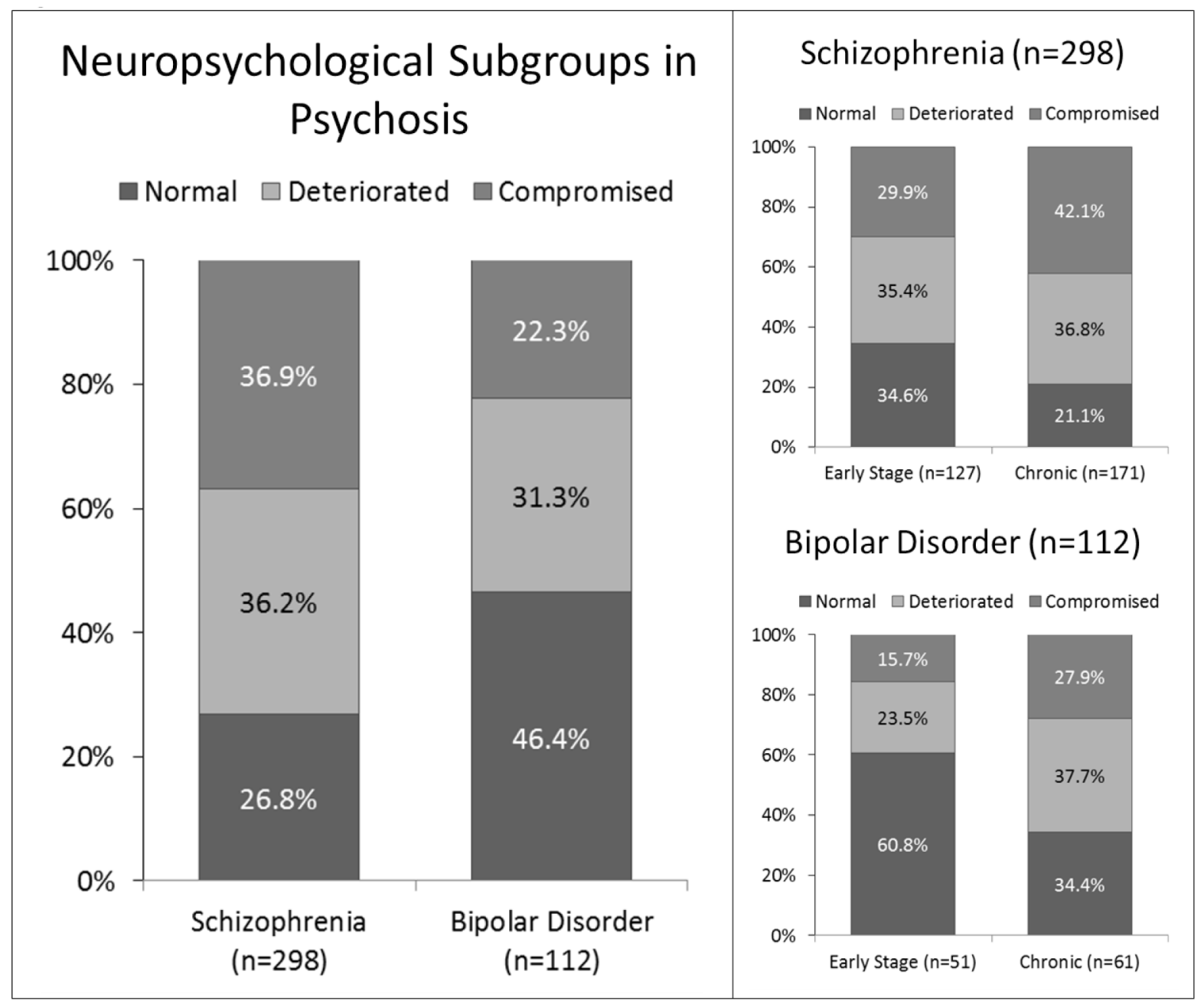

Figure 3.

Neuropsychological subgroups in psychosis. Left panel: The distribution of neuropsychological subgroups differed between schizophrenia and bipolar disorder $(\mathrm{p}<$. 001). Post hoc contrasts revealed that the proportion of neuropsychologically (NP) compromised patients was higher in schizophrenia $(\mathrm{p}<.005)$, whereas the percentage of NP normal patients was higher in bipolar disorder $(\mathrm{p}<.001)$. Right Panel: The proportions of neuropsychological subgroups differed as a function of illness stage in both schizophrenia $(\mathrm{p}=.018)$ and bipolar disorder $(\mathrm{p}=.020)$. In schizophrenia, the chronic cohort included relatively more NP compromised patients $(\mathrm{p}=.031)$ and fewer NP normal patients $(\mathrm{p}=.009)$ compared to the early stage cohort. In psychotic bipolar disorder, the percentage of NP normal patients was higher in early stage than chronic patients $(\mathrm{p}=.005)$. 
Table 1.

Demographic and clinical characteristics for healthy subjects and psychosis patients.

\begin{tabular}{|c|c|c|c|c|c|c|c|c|c|c|}
\hline & \multirow{4}{*}{\multicolumn{2}{|c|}{$\begin{array}{l}\text { Healthy Subjects } \\
\qquad(\mathrm{n}=\mathbf{2 6 1})\end{array}$}} & \multicolumn{8}{|c|}{ Psychosis Patients } \\
\hline & & & \multicolumn{4}{|c|}{ Schizophrenia } & \multicolumn{4}{|c|}{ Psychotic Bipolar Disorder } \\
\hline & & & \multicolumn{2}{|c|}{ Early (n=127) } & \multicolumn{2}{|c|}{ Chronic $(n=171)$} & \multicolumn{2}{|c|}{ Early $(n=51)$} & \multicolumn{2}{|c|}{ Chronic $(n=61)$} \\
\hline & & & Mean & SD & Mean & SD & Mean & SD & Mean & SD \\
\hline Sex (male:female) & \multicolumn{2}{|c|}{$155: 106$} & \multicolumn{2}{|c|}{$106: 21$} & \multicolumn{2}{|c|}{$103: 68$} & \multicolumn{2}{|c|}{$34: 17$} & \multicolumn{2}{|c|}{$21: 40$} \\
\hline Race (White:Other) & \multicolumn{2}{|c|}{$183: 70$} & \multicolumn{2}{|c|}{$87: 40$} & \multicolumn{2}{|c|}{$101: 70$} & \multicolumn{2}{|c|}{$36: 15$} & \multicolumn{2}{|c|}{$50: 11$} \\
\hline Age & 30.20 & 11.35 & 21.17 & 2.99 & 36.56 & 11.61 & 22.47 & 4.74 & 40.51 & 12.58 \\
\hline Education & 15.12 & 2.18 & 13.29 & 2.07 & 12.88 & 2.80 & 13.48 & 2.03 & 14.64 & 2.33 \\
\hline Parental Education & 14.38 & 2.41 & 14.97 & 2.58 & 13.47 & 3.19 & 15.07 & 2.31 & 14.33 & 3.07 \\
\hline Premorbid IQ & 110.19 & 11.59 & 101.42 & 15.12 & 95.47 & 17.17 & 106.02 & 13.41 & 103.82 & 15.62 \\
\hline PANSS Postive & -- & -- & 17.74 & 7.03 & 20.52 & 7.44 & 17.41 & 9.09 & 14.82 & 7.22 \\
\hline PANSS Negative & -- & -- & 17.85 & 7.84 & 15.31 & 6.86 & 11.61 & 5.94 & 10.40 & 3.03 \\
\hline PANSS General & -- & -- & 33.27 & 8.15 & 33.42 & 8.25 & 27.41 & 7.76 & 26.62 & 6.97 \\
\hline HAMD-17 & -- & -- & 8.56 & 5.73 & 9.72 & 6.78 & 7.48 & 5.64 & 8.89 & 6.54 \\
\hline YMRS & -- & -- & 3.44 & 5.36 & 5.64 & 6.56 & 7.08 & 10.33 & 7.00 & 9.40 \\
\hline Duration of Illness, years & -- & -- & 0.44 & 0.49 & 16.19 & 11.05 & 0.38 & 0.53 & 14.52 & 11.48 \\
\hline Chlorpromazine Equivalent & -- & -- & 318.14 & 162.52 & 550.28 & 403.09 & 336.71 & 266.22 & 341.29 & 199.11 \\
\hline
\end{tabular}

Note: Subject education available for 236 healthy subjects, 379 psychosis patients; parental education available for 220 healthy subjects, 349 psychosis patients; duration of illness .available for 405 psychosis patients; PANSS available for 397 psychosis patients; HAMD available for 404; YMRS available for 376 psychosis patients.

Abbreviations: $\mathrm{SD}=$ Standard Deviation 